\title{
Full Debonding Process of Adhesively Bonded Composite and Metallic Pipe Joints under Torsion
}

\author{
Jun Han and Hong Yuan \\ MOE Key Lab of Disaster and Control in Engineering, Institute of Applied Mechanics, Jinan University, Guangzhou, China \\ Correspondence should be addressed to Hong Yuan; tyuanhong@jnu.edu.cn
}

Received 2 September 2016; Revised 27 November 2016; Accepted 13 December 2016

Academic Editor: Alkis S. Paipetis

Copyright (C) 2016 J. Han and H. Yuan. This is an open access article distributed under the Creative Commons Attribution License, which permits unrestricted use, distribution, and reproduction in any medium, provided the original work is properly cited.

\begin{abstract}
Bonded joints are very common in many pipeline systems, in which the bond behavior of the joint interface is of crucial importance. This paper presents two analytical solutions for the debonding process of a pipe joint under torsion, assuming that the bond interface follows either an exponential softening bond-slip law or a simplified bilinear model. The solutions are general, applicable to composites and metallic and indeed other pipes. Based on the analytical solutions, the influences of the bond length and stiffness on the torque-displacement curve and ultimate load are investigated. The solutions can be used to explain the stress transfer mechanism, the interface crack propagation, and the ductility of the joint.
\end{abstract}

\section{Introduction}

Pipes are very important structures in many industries such as energy, aerospace, and construction [1]. In consideration of whole weight, strength, and maintenance workload, it is commonly accepted that there should be less joints in a piping system at first design. Due to the limitation of transportation, installation, and rehabilitation, a joint seems essential for a large structure system containing different components. The limitations of the overall system performance usually come from the capacity of pipe joints. Therefore, the pipe joints play the most important role in the overall integrity of most piping systems [2].

For metallic piping system, the joints can be divided into three types: flange coupling, welding, and adhesive bonding. The first two traditional connections have the same shortage, such as high stress concentration. However, the adhesively bonded pipe joint can effectively lower the stress concentration [3]. While for composite piping system, connecting methods can be roughly summarized as adhesive bonding, butt-strap, heat-activated coupling, and flange coupling. The first three joints are considered as permanent joints and the same joint mechanism is found. Most composite flanges are connected to composite pipe with one of the three permanent methods. Therefore, a general adhesively bonded pipe joint analysis can be used to analyze all the three types of permanent composite pipe joints [4].

Adhesively bonded pipe joints provide uniform load transfer over the bonded area. Nevertheless, stress distribution in the bondline adhesive is nonuniform. Among all the possible loading configurations, such as tension, torsion, and bending, torsion is one of the fundamental types. Due to the difficulties in the analysis of interfacial behavior, few theoretical studies of mode III (torsion) interfacial fracture problems are available in the previous references.

Based on the mechanics of composite materials and the maximum strain failure criterion, an analytical and experimental study was conducted to investigate the elastic and failure behavior of composite laminated pipe under torsion [5]. Based on the general composite shell theory, Zou and Taheri [6] studied the stress concentrations at and near the end of the joints as functions of various parameters, such as the overlap length and thickness of the adhesive layer. Pugno and Surace [7] confirmed that the maximum stresses were attained at the ends of the adhesive and that the peak of maximum stress was reached at the end of the stiffer tube and does not tend to zero as the adhesive length approaches infinity. Cheng and $\mathrm{Li}$ [8] developed an adhesively bonded smart composite pipe joint system by integrating electromechanical coupling piezoelectric layers with the connection coupler. 
Finite element results are good supplements to analytical research. A finite element analysis was used to calculate the residual thermal stresses generated by cooling down from the adhesive cure temperature and a nonlinear analysis incorporating the nonlinear adhesive behavior was performed [9]. Taheri et al. [10-13] developed a simple method for assessing the behavior of adhesively bonded tubular joints under torsion, based on a parametric study conducted by $2 \mathrm{D}$ and 3D finite element analysis. A finite difference method was utilized to solve the system of equilibrium equations and it was modeled as a separate $3 \mathrm{D}$ elastic body without the uniform stress assumption [14].

In all previous solutions, linear elastic properties are assumed for the entire pipe joints. The linear elastic behavior may be appropriate for the pipes themselves. While for the adhesive layer which is usually the weakest link in the bonded joints and often suffers from microcracking and local damage, nonlinear modeling may be necessary. When the crack tip experiences inelastic damage, the concepts based purely on the theory of elasticity are not valid. Therefore, different bond-slip models with softening region were proposed in the previous references, such as rigid-softening, bilinear, trapezoidal, and exponential models [15-24]. The main differences between these models lie in the shape of the tractiondisplacement response and the parameters used to describe that shape. Based on the existing models, some studies have also been presented to solve interfacial debonding problem for the adhesively bonded joints and closed-form solutions are obtained [25-36].

However, there are very few studies focusing on the analytical solution of full debonding process of pipe joints in the literatures. To the best of the authors' knowledge, linear elastic properties are assumed for the entire pipe joints and very few researchers have taken interfacial softening and debonding into consideration. In the present study, there are two analytical solutions for the failure process of adhesively bonded interface, assuming that the bond interface follows either an exponential softening bond-slip law or a simplified bilinear model. The expressions for the interface slip and shear stress are derived for the different failure stages. The present research improves and clarifies the understanding of the interfacial debonding problem of bonded pipe joints under torsion. By modifying different shear modulus, the present results may be further extended to composite pipe joints, composite-metal pipe joints, or metallic pipe joints.

\section{Interface Model of Pipe Joint}

2.1. The Bonded Pipe Joint. Figure 1 shows a bonded pipe joint where two pipes (inner pipes) of the same diameter are joined together symmetrically with a pipe coupler (outer pipe) adhesively bonded to both pipes. Here the inner and outer pipes are defined as Pipes 1 and 2, respectively. Due to symmetry, only the right half of the pipe joint is considered. Let the length of the pipe coupler be $2 L$; the distance between the left end of Pipe 1 and the right end of the Pipe 2 is $L$. Assuming that the pipe coupler is fully bonded with the inner pipes, the bond length between Pipe 1 and Pipe 2 is also $L$ for the right half of the pipe joint.
2.2. Assumptions. The following assumptions are made for the simplicity:

(1) The adherents are homogeneous and linear elastic.

(2) The adhesive is only under pure shear.

(3) The pipe joint is under pure torsion which is resisted by the main pipe and coupler pipe; that is, the adhesive layer is assumed to only transmit shear stresses between Pipes 1 and 2, not contributing to any direct resistance to the torque.

(4) Local bending effects in the pipe joint under the torsional load are neglected.

According to the classical torsion theory, the internal torsion $T_{1}$ and $T_{2}$ in Pipes 1 and 2 can be expressed, respectively, as follows:

$$
\begin{aligned}
& T_{1}=\varphi_{1}^{\prime} G_{1} J_{1} \\
& T_{2}=\varphi_{2}^{\prime} G_{2} J_{2},
\end{aligned}
$$

where subscripts 1 and 2 represent Pipes 1 and 2, respectively; $G$ is the shear modulus of the pipe material; $\varphi^{\prime}$ is the first derivation of the rotational angle with respect to $x$ (Figure $1(\mathrm{c})$ ); and $J$ is polar moment of inertia of the thinwalled pipes which can be expressed as follows:

$$
\begin{aligned}
& J_{1}=2 \pi R_{1}^{3} t_{1} \\
& J_{2}=2 \pi R_{2}^{3} t_{2}
\end{aligned}
$$

in which $t$ is the thickness of the pipes and $R$ is the radius the midline of the pipe cross sections (Figure 1(a)).

As the torque resultant in the soft and thin adhesive layer is ignored following assumption number 3 above, the equilibrium between external and internal torsion load in the pipe joint requires

$$
\begin{aligned}
T_{1}+T_{2} & =0 \\
\frac{d T_{1}}{d x}+\frac{d T_{2}}{d x} & =0 .
\end{aligned}
$$

2.3. Governing Equations. Let the relative rotation between Pipes 1 and 2 at $x$ be $\varphi$ as illustrated in Figure 2. Consider the torsional equilibrium of an infinitely small section $d x$ in Pipe 1 (Figure 2):

$$
2 \pi R \tau R d x=d T_{1}
$$

where $\tau$ is the interfacial shear stress in the circumferential direction and $R$ is the distance between the center of the pipe and midline of the adhesive layer which can be calculated by

$$
R=\frac{1}{2}\left[\left(R_{1}+\frac{t_{1}}{2}\right)+\left(R_{2}-\frac{t_{2}}{2}\right)\right] .
$$




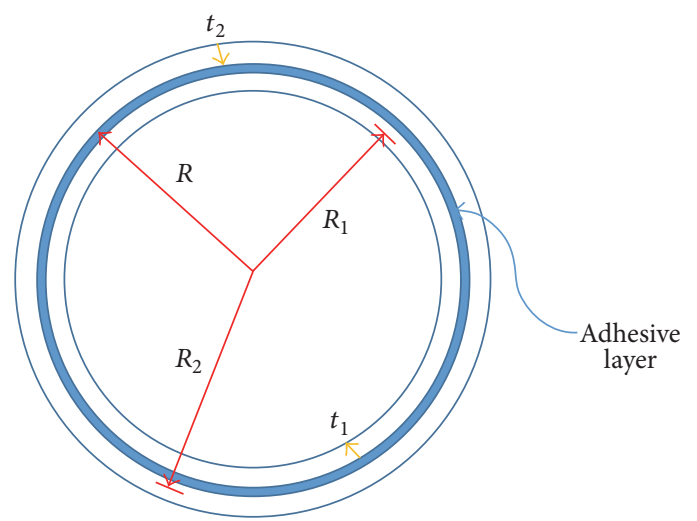

(a) Cross section

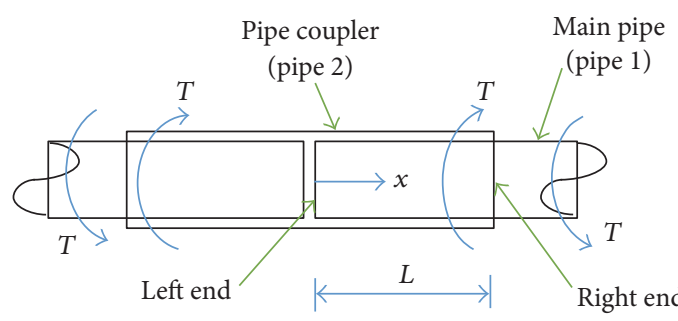

(b) Side view

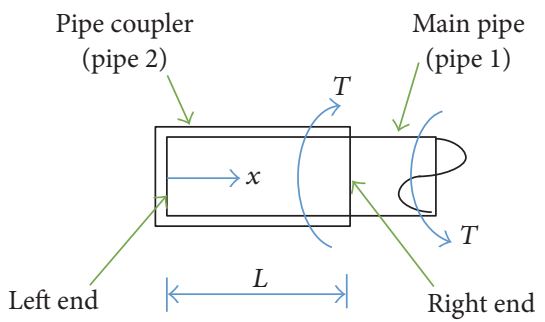

(c) Right half of the pipe joint

FIgURE 1: An adhesively bonded pipe joint.

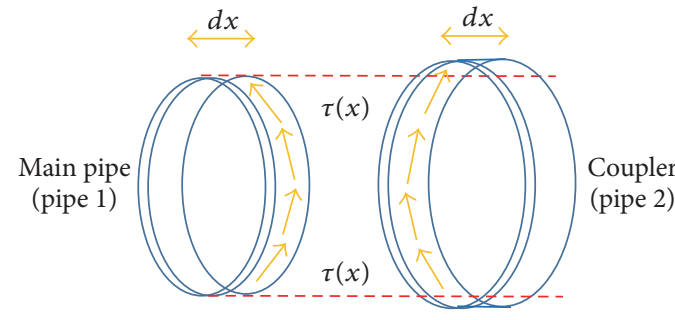

(a)

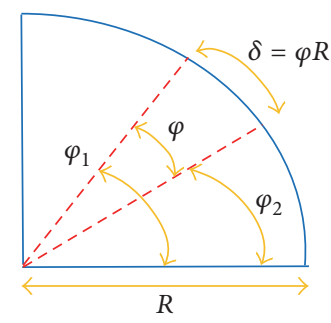

(b)

FIGURE 2: Equilibrium of local interfacial shear stresses.

The relative slip at the bond interface in the circumferential direction as $\delta$ can be found from the relative interfacial rotation $\varphi$ :

$$
\delta=R \varphi=R \varphi_{1}-R \varphi_{2} .
$$

After substituting (1)-(4) into (5) and introducing the parameter $\lambda$, local bond strength $\tau_{f}$, and interfacial fracture energy $G_{f}$, we have

$$
\begin{aligned}
\frac{d^{2} \delta}{d x^{2}}-\frac{2 G_{f}}{\tau_{f}^{2}} \lambda^{2} f(\delta) & =0 \\
\varphi_{1}^{\prime} & =\frac{\tau_{f}^{2}}{2 G_{f} \lambda^{2}} \frac{2 \pi R^{2}}{G_{1} J_{1}} \frac{d \delta}{d x},
\end{aligned}
$$

where

$$
\lambda^{2}=2 \pi R^{3} \frac{G_{1} J_{1}+G_{2} J_{2}}{G_{1} J_{1} G_{2} J_{2}} \frac{\tau_{f}^{2}}{2 G_{f}} .
$$

Substituting (9) into (1), the relationship of $T_{1}$ and derivative of $\delta$ can be obtained:

$$
T_{1}=2 \pi R^{2} \frac{\tau_{f}^{2}}{2 G_{f} \lambda^{2}} \frac{d \delta}{d x} .
$$

Equation (8) is the governing differential equation of the adhesively bonded joint. It can be solved once the local bondslip model is given.

2.4. Bond-Slip Model. As introduced before, researchers have proposed various bond-slip models. Experimental results indicate that the bilinear model which features a linear 


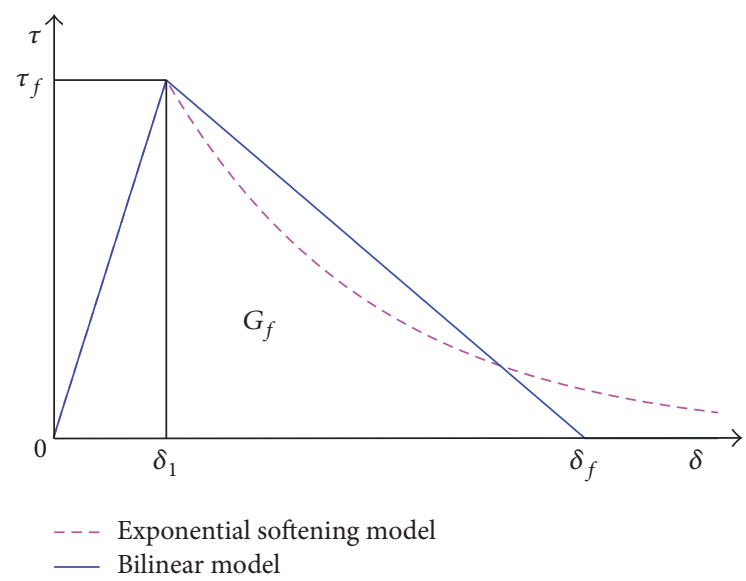

Figure 3: Bond-slip models.

ascending branch followed by a linear descending branch provides a close approximation [31]. However, the use of linear softening law may lead to overestimating the mechanical properties of the joint. Therefore, a bond-slip law characterised by a linear phase, with slope $\alpha$, followed by an exponential softening branch is used [35]. And the results based on the two models are compared in order to provide better understanding of failure process.

For the exponential bond-slip law (Figure 3), the interfacial shear stress increases linearly with slip within the elastic range. The shear stress peaks at $\tau_{f}$ at which the value of the slip is denoted by $\delta_{1}$. This stage is defined as elastic stage which is simplified as E. The interface enters the softening stage thereafter and the interfacial shear stress decays exponentially with the interfacial slip. This stage is defined as softening stage which is simplified as S. The mathematical expressions of the interfacial bond-slip law in Figure 3 are

$$
\tau=f(\delta)= \begin{cases}\frac{\tau_{f}}{\delta_{1}} \delta & \left(0 \leq \delta \leq \delta_{1}\right) \\ \tau_{f} e^{-2 \alpha^{2}\left(\delta / \delta_{1}-1\right)} & \left(\delta>\delta_{1}\right) .\end{cases}
$$

The bilinear model (Figure 3) features a linear ascending branch followed by a linear descending branch to zero at a slip $\delta_{f}$. This stage is defined as debonding stage which is simplified as D. It is usually treated as a simplified model of the exponential softening model. The results are usually very close if the fracture energy $G_{f}$ is the same for the two models [28]. This bond-slip model is mathematically described by the following:

$$
\tau=f(\delta)= \begin{cases}\frac{\tau_{f}}{\delta_{1}} \delta & \left(0 \leq \delta \leq \delta_{1}\right) \\ \frac{\tau_{f}}{\delta_{f}-\delta_{1}}\left(\delta_{f}-\delta\right) & \left(\delta_{1}<\delta \leq \delta_{f}\right) \\ 0 & \left(\delta>\delta_{f}\right) .\end{cases}
$$

The positive coefficient $\alpha^{2}$ in (12) characterises the exponential decay can be related to the slip parameters of the bilinear model by letting the interfacial fracture energy $G_{f}$ be equal for the two models:

$$
\alpha^{2}=\frac{\delta_{1}}{\delta_{f}-\delta_{1}} .
$$

\section{Debonding Process: The Exponential Model}

3.1. Elastic Stage. At small loads, there is no interfacial softening or debonding along the interface, so the entire length of the interface is in an elastic stress state. Substituting the first expression in (12) into (8) gives the following differential equation:

$$
\delta^{\prime \prime}(x)-\lambda_{1}^{2} \delta(x)=0 \quad\left(0 \leq \delta \leq \delta_{1}\right),
$$

where

$$
\lambda_{1}^{2}=2 \pi R^{3} \frac{G_{1} J_{1}+G_{2} J_{2}}{G_{1} J_{1} G_{2} J_{2}} \frac{\tau_{f}}{\delta_{1}} .
$$

The inner pipe is free from stress at $x=0$ and subjected to a torque $T$ at $x=L$, so the boundary conditions can be expressed as

$$
\begin{aligned}
\varphi_{1}^{\prime}(0) & =0 \\
\varphi_{1}^{\prime}(L) & =\frac{T}{G_{1} J_{1}} .
\end{aligned}
$$

Based on these boundary conditions, the solution of (15) for the relative shear displacement and shear stress of the adhesive layer can be written in the form

$$
\begin{gathered}
\delta(x)=\frac{T \delta_{1} \lambda_{1}}{2 \pi R^{2} \tau_{f}} \frac{\cosh \left(\lambda_{1} x\right)}{\sinh \left(\lambda_{1} L\right)} \\
\tau(x)=\frac{T \lambda_{1}}{2 \pi R^{2}} \frac{\cosh \left(\lambda_{1} x\right)}{\sinh \left(\lambda_{1} L\right)} .
\end{gathered}
$$

The interfacial slip at the free end of the outer pipe (i.e., the value of $\delta$ at $x=L$ ) is defined as the displacement of the bonded joint for convenience and denoted by $\Delta$ here. From (19), the torque-displacement is expressed as

$$
T=\frac{2 \pi R^{2} \tau_{f}}{\delta_{1} \lambda_{1}} \tanh \left(\lambda_{1} L\right) \Delta .
$$

3.2. Elastic-Softening Stage. As the load increases, the interfacial slip reaches $\delta_{1}$ at $x=L$ and the bond enters the softening stage there. The whole interface is in an elastic-softening stage and the length of the softening region $a$ increases with the increase of torque $T$. Substituting (12) into (8) gives (15) and the following equation for this stage:

$$
\delta^{\prime \prime}(x)-\lambda_{2}^{2} e^{-2 \alpha^{2}\left(\delta(x) / \delta_{1}\right)}=0 \quad\left(\delta>\delta_{1}\right),
$$


where

$$
\lambda_{2}^{2}=2 \pi R^{3} \frac{G_{1} J_{1}+G_{2} J_{2}}{G_{1} J_{1} G_{2} J_{2}} \tau_{f} e^{2 \alpha^{2}} .
$$

Applying the boundary conditions of (17) and (18) and the following continuity conditions:

$$
\begin{aligned}
\delta(L-a) & =\delta_{1} \\
\delta^{\prime}(x) \text { is continues at } x & =L-a,
\end{aligned}
$$

the solution for the elastic region of the interface $\left(0 \leq \delta \leq \delta_{1}\right.$, i.e., $0 \leq x \leq L-a)$ is obtained as

$$
\begin{gathered}
\delta(x)=\frac{\delta_{1} \cosh \left(\lambda_{1} x\right)}{\cosh \left[\lambda_{1}(L-a)\right]} \\
\tau(x)=\frac{\tau_{f} \cosh \left(\lambda_{1} x\right)}{\cosh \left[\lambda_{1}(L-a)\right]}
\end{gathered}
$$

and the solution for the softening region of the interface $(\delta>$ $\delta_{1}$, i.e., $\left.L-a \leq x \leq L\right)$ is

$$
\begin{aligned}
& \delta(x)=\frac{1}{n} \ln \left(\frac{2 m}{n c_{1}}\right)+\frac{2}{n} \ln \left\{\cosh \left[\frac{n}{2} \sqrt{c_{1}}\left(x-c_{2}\right)\right]\right\} \\
& \tau(x)=\tau_{f} e^{-2 \alpha^{2}\left[\delta(x) / \delta_{1}-1\right]},
\end{aligned}
$$

where

$$
\begin{aligned}
& m=\lambda_{2}^{2} \\
& n=\frac{2 \alpha^{2}}{\delta_{1}} .
\end{aligned}
$$

Using (24), the constants $c_{1}$ and $c_{2}$ can be obtained as

$$
\begin{aligned}
& c_{1}=\left\{\delta_{1} \lambda_{1} \tanh \left[\lambda_{1}(L-a)\right]\right\}^{2}+\frac{2 m}{n} e^{-n \delta_{1}} \\
& c_{2}=L-a-\frac{2}{n \sqrt{c_{1}}} \operatorname{arccosh}\left(\sqrt{\frac{n c_{1}}{2 m} e^{n \delta_{1}}}\right) .
\end{aligned}
$$

The expression of slip at $x=L$ can be obtained from (26) as

$$
\begin{aligned}
\Delta & =\delta(L) \\
& =\frac{1}{n} \ln \left(\frac{2 m}{n c_{1}}\right)+\frac{2}{n} \ln \left\{\cosh \left[\frac{n}{2} \sqrt{c_{1}}\left(L-c_{2}\right)\right]\right\} .
\end{aligned}
$$

Substituting (18) and (26) into (9) yields

$$
T=\frac{2 \pi R^{2} \tau_{f}}{\delta_{f} \lambda^{2}} \sqrt{-\frac{2 m}{n} e^{-n \Delta}+c_{1}} .
$$

For exponential model, by substituting (31) into (32), the expression of $T$ above can be rewritten as

$$
T=\frac{2 \pi R^{2} \tau_{f}}{\delta_{f} \lambda^{2}} \sqrt{c_{1}} \tanh \left[\frac{n}{2} \sqrt{c_{1}}\left(L-c_{2}\right)\right] .
$$

When $L$ is sufficiently large (approaches to infinity), (33) and (29) converge to

$$
T_{u}=\frac{2 \pi R^{2} \tau_{f}}{\delta_{f} \lambda^{2}} \sqrt{c_{1}}
$$

where

$$
c_{1}=\left(\delta_{1} \lambda_{1}\right)^{2}+\frac{2 m}{n} e^{-n \delta_{1}}
$$

in which $T_{u}$ is the maximum possible value (the asymptotic value) $T$ can reach.

In bonded joints, there is usually an effective bond length $l_{e}$, which is defined as the length beyond which an increase of the bond length the loading capacity of the bonded joint does not increase further [37]. For the exponential bond-slip law employed here, the loading (torque) capacity always increases with the bond length $L$, but the rate of increase would be very small if $L$ is sufficiently large. Following Yuan et al. 2004, the effective bond length is defined here as the bond length which provides a resistance of $97 \%$ of $T_{u}$. Following this definition, $l_{e}$ can be obtained from (30) and (33)-(35) as

$$
l_{e}=a_{e}+\frac{2}{\lambda_{1}}
$$

where

$$
a_{e}=\frac{4}{n \sqrt{c_{1}}}-\frac{2}{n \sqrt{c_{1}}} \operatorname{arccosh}\left(\sqrt{\frac{n c_{1}}{2 m} e^{n \delta_{1}}}\right) .
$$

3.3. Softening Stage. As the load increases, the peak of the shear stress moves towards the middle of the joint $(x=0)$. When the interfacial slip at $x=0$ reaches $\delta_{1}$, the whole interface enters into softening. This stage is governed by (22) with the boundary conditions of (17) and (18). The solution for the interfacial slip and the shear stress of the bond interface can be obtained as

$$
\begin{aligned}
& \delta(x)=\frac{1}{n} \ln \left(\frac{2 m}{n c_{3}}\right)+\frac{2}{n} \ln \left\{\cosh \left[\frac{n}{2} \sqrt{c_{3}}\left(x-c_{4}\right)\right]\right\} \\
& \tau(x)=\tau_{f} e^{-2 \alpha^{2}\left[\delta(x) / \delta_{1}-1\right]},
\end{aligned}
$$

where the constants $c_{3}$ and $c_{4}$ are

$$
\begin{aligned}
c_{3} \tanh ^{2}\left[\frac{n \sqrt{c_{3}}}{2}\left(L-c_{4}\right)\right] & =\left(\frac{T \delta_{f} \lambda^{2}}{2 \pi R^{2} \tau_{f}}\right)^{2} . \\
c_{4} & =0
\end{aligned}
$$

Substituting (18) and (38) into (9) yields

$$
T=\frac{2 \pi R^{2} \tau_{f}}{\delta_{f} \lambda^{2}} \sqrt{-\frac{2 m}{n} e^{-n \Delta}+c_{3}} .
$$


The expression of the slip at $x=L$ can be obtained from (38):

$$
\Delta=\frac{1}{n} \ln \left(\frac{2 m}{n c_{3}}\right)+\frac{2}{n} \ln \left\{\cosh \left[\frac{n}{2} \sqrt{c_{3}}\left(L-c_{4}\right)\right]\right\} .
$$

\section{Debonding Process: Bilinear Model}

4.1. Elastic Stage. The solution for the elastic stage is the same as that in Section 3.1.

4.2. Elastic-Softening Stage. As the load increases, softening commences at $x=L$ once the shear stress reaches $\tau_{f}$ there. $T$ increases as the softening length $a$ increases. Substituting the first or the second expression in (13) into (8) gives (15) and the following:

$$
\delta^{\prime \prime}(x)-\lambda_{3}^{2}\left[\delta_{f}-\delta(x)\right]=0 \quad\left(\delta_{1}<\delta \leq \delta_{f}\right),
$$

where

$$
\lambda_{3}^{2}=2 \pi R^{3} \frac{G_{1} J_{1}+G_{2} J_{2}}{G_{1} J_{1} G_{2} J_{2}} \frac{\tau_{f}}{\delta_{f}-\delta_{1}} .
$$

With the same boundary and continuity conditions as in Section 3.2, the solution for the elastic region of the interface $\left(0 \leq \delta \leq \delta_{1}\right.$, i.e., $\left.0 \leq x \leq L-a\right)$ is the same as that in Section 3.2, and the solution for the softening region of the interface $\left(\delta_{1}<\delta \leq \delta_{f}\right.$, i.e., $\left.L-a \leq x \leq L\right)$ is given by

$$
\begin{aligned}
& \delta(x)=\left(\delta_{f}-\delta_{1}\right) \\
& \cdot\left\{\frac{\lambda_{3}}{\lambda_{1}} \tanh \left[\lambda_{1}(L-a)\right] \sin \left[\lambda_{3}(x-L+a)\right]\right. \\
& \left.\quad-\cos \left[\lambda_{3}(x-L+a)\right]+\frac{\delta_{f}}{\delta_{f}-\delta_{1}}\right\} \\
& \tau(x) \quad-\tau_{f}\left\{\frac{\lambda_{3}}{\lambda_{1}} \tanh \left[\lambda_{1}(L-a)\right] \sin \left[\lambda_{3}(x-L+a)\right]\right. \\
& \left.\quad-\cos \left[\lambda_{3}(x-L+a)\right]\right\} .
\end{aligned}
$$

Substituting (18) and (45) into (9) yields

$$
\begin{aligned}
T= & \frac{2 \pi R^{2} \tau_{f}}{\lambda_{3}}\left\{\frac{\lambda_{3}}{\lambda_{1}} \tanh \left[\lambda_{1}(L-a)\right] \cos \left(\lambda_{3} a\right)\right. \\
& \left.+\sin \left(\lambda_{3} a\right)\right\} .
\end{aligned}
$$

The expression of the slip at $x=L$ can be obtained from (45):

$$
\begin{aligned}
\Delta & =\left(\delta_{f}-\delta_{1}\right)\left\{\frac{\lambda_{3}}{\lambda_{1}} \tanh \left[\lambda_{1}(L-a)\right] \sin \left(\lambda_{3} a\right)\right. \\
& \left.-\cos \left(\lambda_{3} a\right)+\frac{\delta_{f}}{\delta_{f}-\delta_{1}}\right\} .
\end{aligned}
$$

During this stage, the torque-displacement curve can be determined from (47) and (48). When the interfacial slip increases to $\delta_{f}$ at $x=L$ but the slip at $x=0$ is less than $\delta_{1}$, the interface enters into elastic-softening-debonding stage. When the slip at $x=0$ reaches $\delta_{1}$ and the slip at $x=L$ is less than $\delta_{f}$, the interface enters into softening stage. Therefore, there exists a critical bond length to distinguish the failure process:

$$
L_{c r}=\frac{\pi}{2 \lambda_{3}}
$$

When the bond length is larger than $L_{c r}$, the interface enters into elastic-softening-debonding stage. When the bond length is shorter than $L_{c r}$, the interface enters into softening stage. For the bilinear model, $T$ reaches its maximum when the derivative of (47) with respect to $a$ equals zero. Therefore, $a$ at the ultimate load can be found from the following relationship:

$$
\tanh \left[\lambda_{1}(L-a)\right]=\frac{\lambda_{3}}{\lambda_{1}} \tan \left(\lambda_{3} a\right)
$$

Substituting (50) into (47) yields

$$
T=\frac{2 \pi R^{2} \tau_{f}}{\lambda_{3}} \frac{\delta_{f}}{\delta_{f}-\delta_{1}} \sin \left(\lambda_{3} a\right)
$$

It can be shown from (50) and (51) that $T$ approaches the following value when $L$ is large:

$$
T_{u}=\frac{2 \pi R^{2} \tau_{f}}{\lambda} .
$$

Following the same definition in (36) and considering that $\tanh (2) \approx 0.97$, the effective bond length when $0.97 T_{u}$ is reached can be obtained from (50)-(52) to give

$$
l_{e}=a_{e}+\frac{1}{2 \lambda_{1}} \ln \left[\frac{\lambda_{1}+\lambda_{3} \tan \left(\lambda_{3} a_{e}\right)}{\lambda_{1}-\lambda_{3} \tan \left(\lambda_{3} a_{e}\right)}\right],
$$

where

$$
a_{e}=\frac{1}{\lambda_{3}} \arcsin \left[0.97 \sqrt{\frac{\delta_{f}-\delta_{1}}{\delta_{f}}}\right]
$$

\subsection{Joints with $L>L_{c r}$}

4.3.1. Elastic-Softening-Debonding Stage. If $L>L_{c r}$, as the torque increases, the interfacial slip at $x=L$ reaches $\delta_{f}$ which represents the initiation of debonding (or macrocracking or fracture). Because $\Delta=\delta_{f}$ at the initiation of debonding, the corresponding value of $a$, denoted by $a_{d}$, can be obtained from (48) as

$$
\frac{\lambda_{3}}{\lambda_{1}} \tanh \left[\lambda_{1}\left(L-a_{d}\right)\right] \sin \left(\lambda_{3} a_{d}\right)-\cos \left(\lambda_{3} a_{d}\right)=0
$$


Debonding propagates hereafter and the peak shear stress moves towards $x=0$. Assuming that the debonded length of the interface starting at $x=L$ is $d,(25)$ and (45)-(46) are still valid if replacing $L$ by $L-d$. Therefore, the torquedisplacement relationship can be written as

$$
\begin{aligned}
T & =\frac{2 \pi R^{2} \tau_{f}}{\lambda_{3}}\left\{\frac{\lambda_{3}}{\lambda_{1}} \tanh \left[\lambda_{1}(L-d-a)\right] \cos \left(\lambda_{3} a\right)\right. \\
& \left.+\sin \left(\lambda_{3} a\right)\right\} \\
\Delta & =\delta_{f}+\frac{\delta_{f} T \lambda^{2}}{2 \pi R^{2} \tau_{f}} d .
\end{aligned}
$$

As the interfacial shear stress at $x=L-d$ is zero, the following relationship can be obtained:

$$
\frac{\lambda_{3}}{\lambda_{1}} \tanh \left[\lambda_{1}(L-d-a)\right] \sin \left(\lambda_{3} a\right)-\cos \left(\lambda_{3} a\right)=0
$$

Substituting (58) into (56) yields the following simplified form:

$$
T=\frac{2 \pi R^{2} \tau_{f}}{\lambda_{3}} \frac{1}{\sin \left(\lambda_{3} a\right)} .
$$

At the end of this stage, the softening-debonding stage starts when $L-d=a_{u}$. Substituting this into (58) yields

$$
a_{u}=\frac{\pi}{2 \lambda_{3}} \text {. }
$$

Moreover, by substituting (60) into (59), (59) can be written as

$$
T=\frac{2 \pi R^{2} \tau_{f}}{\lambda_{3}}
$$

4.3.2. Softening-Debonding Stage. This stage is governed by (43) with the boundary conditions of (17) and

$$
\begin{aligned}
\varphi_{1}^{\prime}(a) & =\frac{T}{G_{1} J_{1}} \\
\delta(a) & =\delta_{f} .
\end{aligned}
$$

Based on the boundary conditions, the following solution can thus be found by solving the governing equation (43):

$$
\begin{aligned}
a & =\frac{\pi}{2 \lambda_{3}}=a_{u} \\
\delta(x) & =\delta_{f}-\frac{\delta_{f} T \lambda^{2}}{2 \pi R^{2} \tau_{f} \lambda_{3}} \cos \left(\lambda_{3} x\right) \quad\left(0 \leq x \leq a_{u}\right) \\
\tau(x) & =\frac{\lambda_{3} T}{2 \pi R^{2} \cos \left(\lambda_{3} x\right)} \quad\left(0 \leq x \leq a_{u}\right) .
\end{aligned}
$$

From (64) it is seen that the length of softening zone remains constant during this stage. The torque-displacement relationship can be obtained by solving (8) for the case of $\delta>$ $\delta_{f}$ or directly displacement superposition along the bonded joint:

$$
\Delta=\delta_{f}+\frac{\delta_{f} T \lambda^{2}}{2 \pi R^{2} \tau_{f}}\left(L-a_{u}\right) .
$$

\subsection{For Joints with $L<L_{c r}$}

4.4.1. Softening Stage. As the load increases, the shear stress peak moves towards $x=0$. When the interfacial slip at $x=0$ reaches $\delta_{1}$, the whole interface enters into the softening zone. This stage is governed by (43) with boundary conditions of (17) and (18). Based on the boundary conditions, the following solution can be obtained by solving the governing equation (43):

$$
\begin{aligned}
& \delta(x)=\delta_{f}-\frac{T \lambda^{2} \delta_{f} \cos \left(\lambda_{3} x\right)}{2 \pi R^{2} \tau_{f} \lambda_{3} \sin \left(\lambda_{3} L\right)} \\
& \tau(x)=\frac{T \lambda_{3} \cos \left(\lambda_{3} x\right)}{2 \pi R^{2} \sin \left(\lambda_{3} L\right)} .
\end{aligned}
$$

The expression of the slip at $x=L$ can be obtained from (68):

$$
\Delta=\delta_{f}-\frac{T \lambda^{2} \delta_{f}}{2 \pi R^{2} \tau_{f} \lambda_{3}} \cot \left(\lambda_{3} L\right) .
$$

As shown in the bond-slip law, when the interface slip reaches $\delta_{f}$, debonding occurs. Substituting this condition into (70), the external load reduces to zero. Hence, it can be concluded that the softening stage here always represents the ultimate failure stage.

\section{Numerical Simulations}

The results of an adhesively bonded metal-composite pipe joint are presented here. The typical inner diameter and thickness are assumed to be 300 and $10 \mathrm{~mm}$ for the metallic main pipe, respectively. And the inner diameter and thickness of the composite coupler are assumed to be 320.4 and $5 \mathrm{~mm}$, respectively. For metallic main pipe, the mechanical properties are chosen as $E_{11}=E_{22}=200 \mathrm{GPa}, G_{12}=$ $75 \mathrm{GPa}$, and $\mu_{12}=0.3$. For composite coupler, the mechanical properties are chosen as $E_{11}=25.2 \mathrm{GPa}, E_{22}=7.5 \mathrm{GPa}$, $G_{12}=2.4 \mathrm{GPa}$, and $\mu_{12}=0.32$. The parameters for interfacial bond-slip laws are identified as $\tau_{f}=7.2 \mathrm{MPa}, \delta_{1}=0.034 \mathrm{~mm}$, and $\delta_{f}=0.16 \mathrm{~mm}$.

According to the material properties and geometry parameters given above, the critical bond length for bilinear model can be calculated as $L_{c r}=23 \mathrm{~mm}$. Therefore, bond lengths of 20 and $80 \mathrm{~mm}$ are chosen.

\subsection{Load-Displacement Curves}

5.1.1. Load-Displacement Curves for Exponential Model. The load-displacement curve for exponential model is shown in 


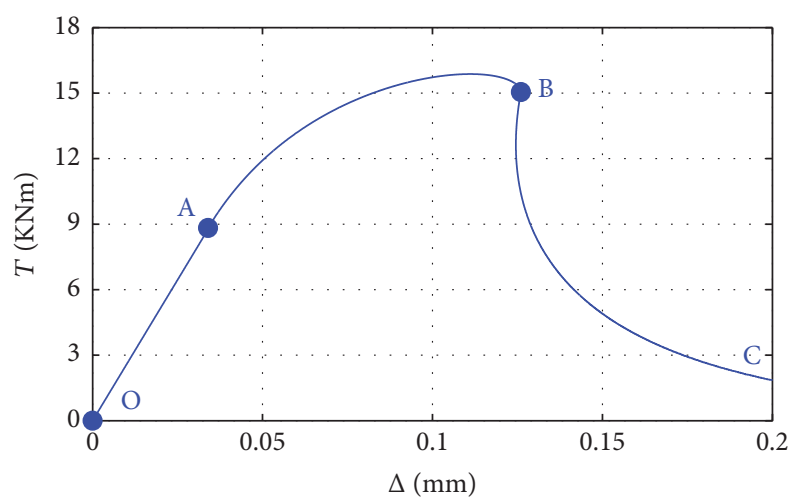

(a) $L=20 \mathrm{~mm}$

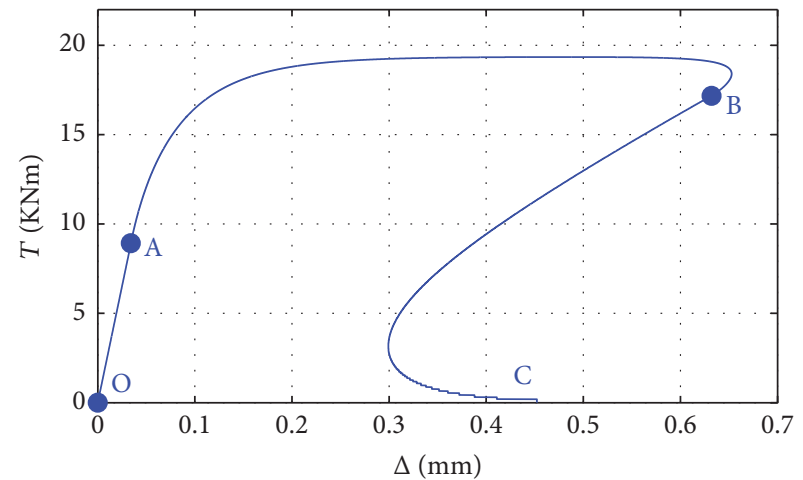

(b) $L=80 \mathrm{~mm}$

FIGURE 4: Load-displacement curves: exponential model.

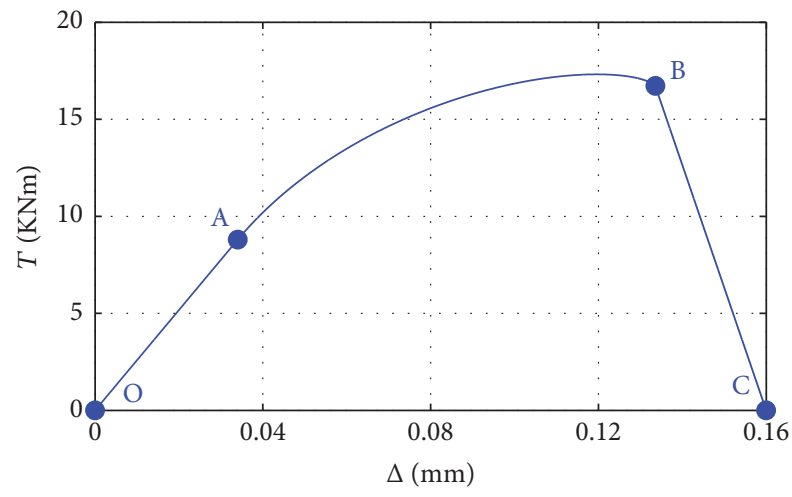

(a) $L=20 \mathrm{~mm}$

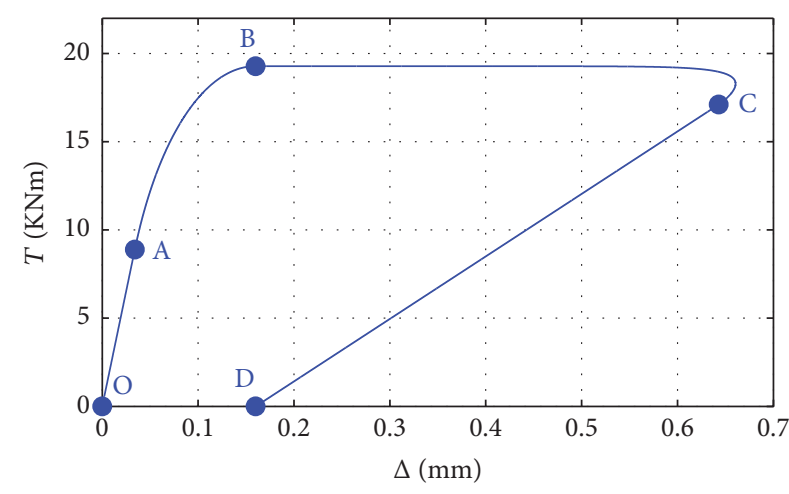

(b) $L=80 \mathrm{~mm}$

FIGURE 5: Load-displacement curves: bilinear model.

Figure 4. $\mathrm{OA}, \mathrm{AB}$, and $\mathrm{BC}$ are elastic, elastic-softening, and softening stages, respectively.

5.1.2. Load-Displacement Curves for Bilinear Model. When the bond length is shorter than $L_{c r}$, take $L=20 \mathrm{~mm}$ and the load-displacement curve is shown in Figure 5(a). OA, AB, and $\mathrm{BC}$ are elastic, elastic-softening, and softening stages, respectively. When the bong length is longer than $L_{c r}$, take $L=80 \mathrm{~mm}$ and the load-displacement curve is shown in Figure 5(b). OA, AB, BC, and CD are elastic, elastic-softening, elastic-softening-debonding, and softening-debonding stages, respectively.

5.2. Shear Stress Distribution. The shear stress distribution for exponential model is shown in Figure 6. When the load is small, the interfacial shear stress at loaded end is less than peak stress and the interface is in an elastic stage. When the interfacial shear stress reaches peak stress at loaded end, the interface enters into elastic-softening stage. As load increases, the peak stress moves from loaded end to unloaded end and the length of softening zone increases. When the interfacial shear stress at unloaded end reaches peak stress, the interface enters into softening stage. For simplified legend, the critical status is defined as the end. For example, the critical status between elastic stage and elastic-softening stage is defined as E-end in Figure 6(a). And the following abbreviations are the same.

The shear stress distribution of $L=20 \mathrm{~mm}$ and $L=$ $80 \mathrm{~mm}$ for bilinear model are shown in Figures 7(a) and 7(b), respectively. When the load is small, the interfacial shear stress at loaded end is less than peak stress and the interface is an in elastic stage. When the interfacial shear stress reaches peak stress at loaded end, the interface enters into elasticsoftening stage. As load increases, the peak stress moves from loaded end to unloaded end and the length of softening zone increases. When the interfacial shear stress at unloaded end reaches peak stress while $\Delta<\delta_{f}$, the interface enters into softening stage shown as in Figure 7(a). When $\Delta=\delta_{f}$ and the interfacial shear stress at unloaded end is less than peak stress, then the interface enters into elastic-softening-debonding stage as shown in Figure 7(b). The length of debonding zone increases as the peak stress moves to unloaded end. When the interfacial shear stress at unloaded end reaches peak stress, the interface enters into softening-debonding stage.

5.3. Parametric Study. Figure 8(a) shows the influence for different bond lengths of bilinear model on the load-displacement curves. From the figure, the significant influence for 


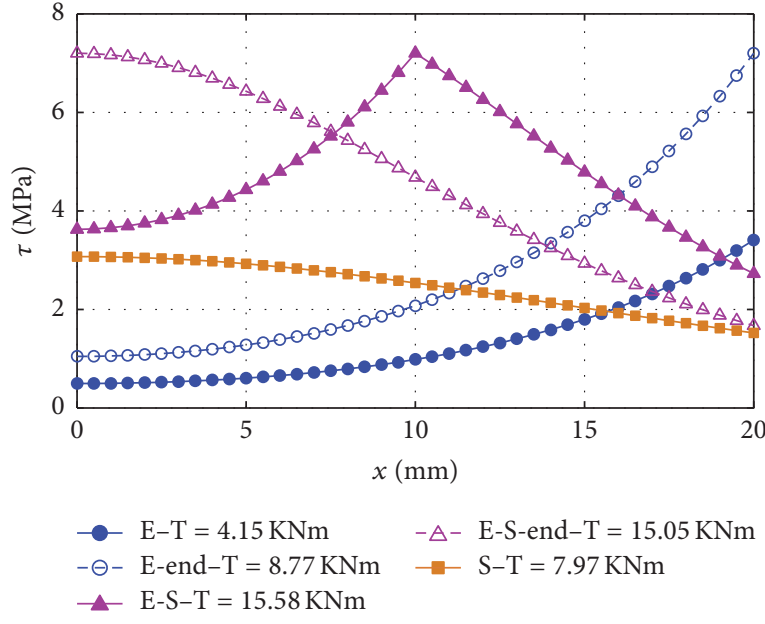

(a) $L=20 \mathrm{~mm}$

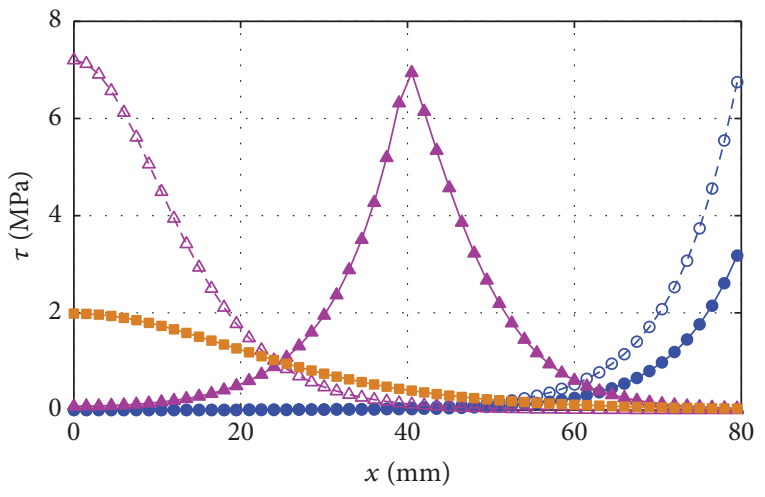

$-\mathrm{E}-\mathrm{T}=4.17 \mathrm{KNm} \quad-A-\quad \mathrm{E}-\mathrm{S}$-end $-\mathrm{T}=17.18 \mathrm{KNm}$ $-\Theta-$ E-end $-\mathrm{T}=8.86 \mathrm{KNm} \rightarrow \mathrm{S}-\mathrm{T}=8.96 \mathrm{KNm}$ $\neg$ E-S-T $=19.32 \mathrm{KNm}$

(b) $L=80 \mathrm{~mm}$

FIGURE 6: Shear stress distribution: exponential model.

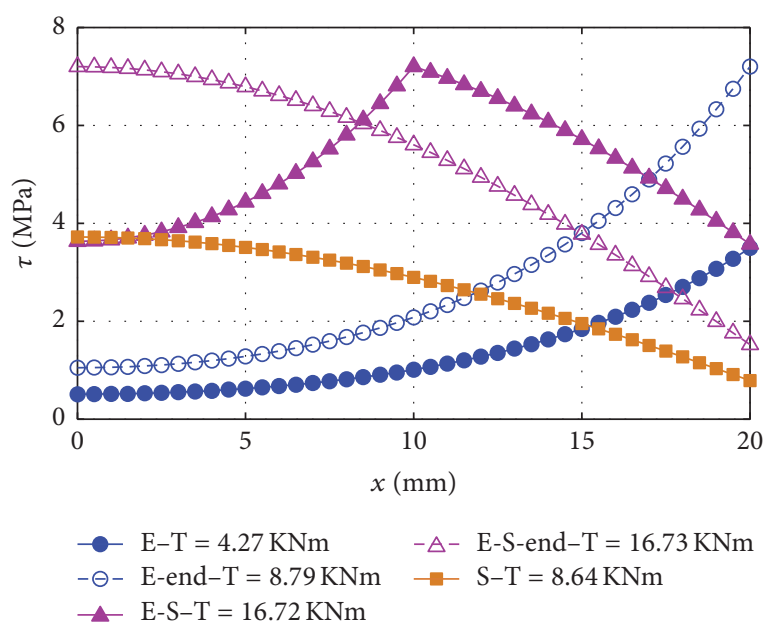

(a) $L=20 \mathrm{~mm}$
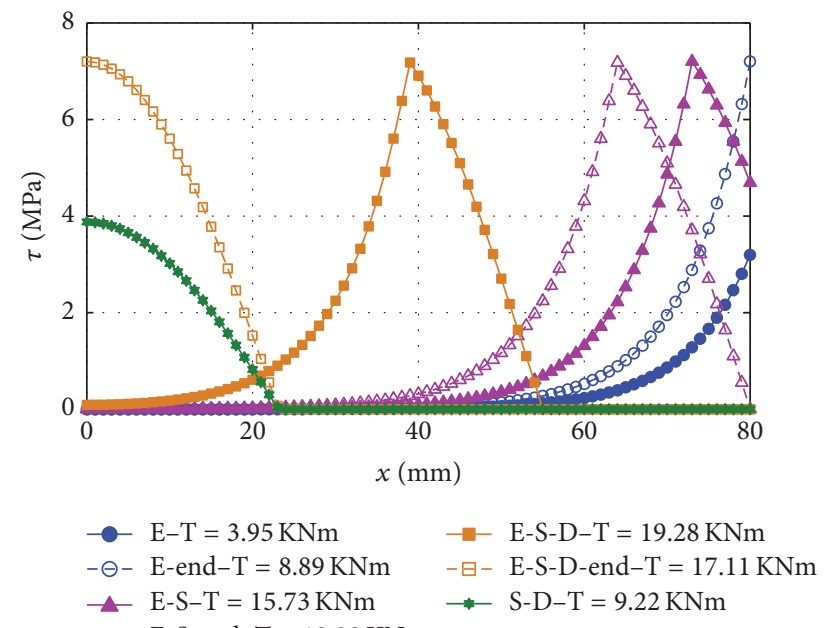

$-\Delta$ - E-S-end- $\mathrm{T}=19.28 \mathrm{KNm}$

(b) $L=80 \mathrm{~mm}$

FIGURE 7: Shear stress distribution: bilinear model.

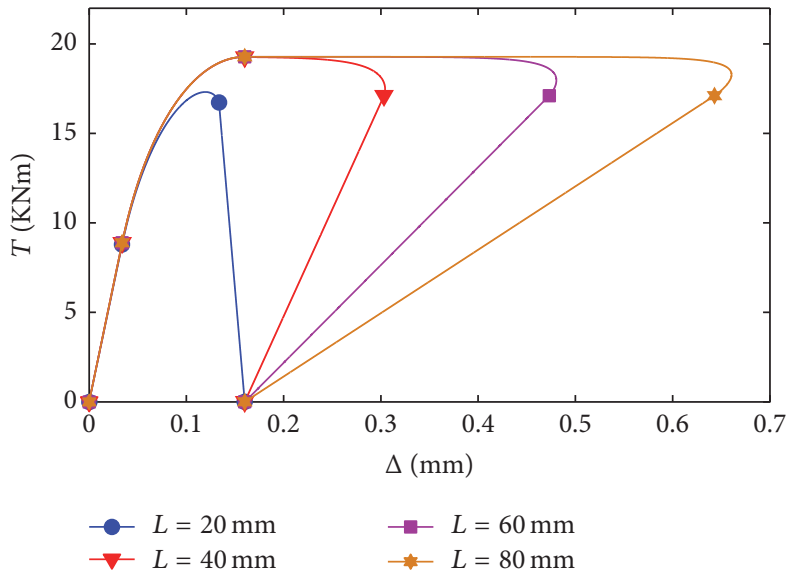

(a) Bilinear model

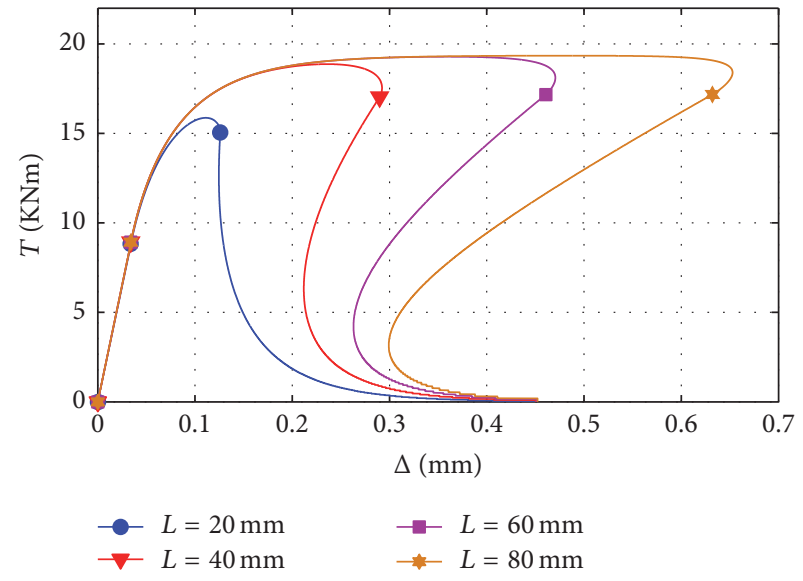

(b) Exponential model

Figure 8: Effect of bond length on load-displacement. 


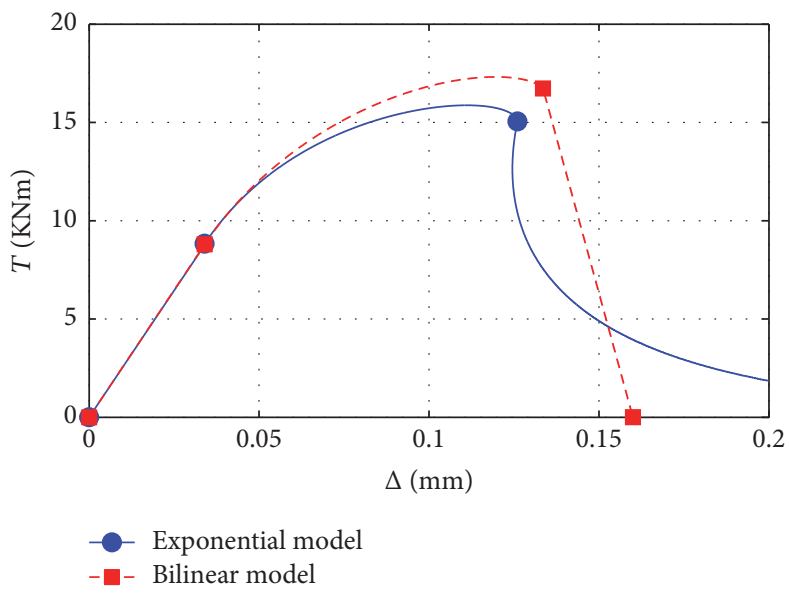

(a) $L=20 \mathrm{~mm}$

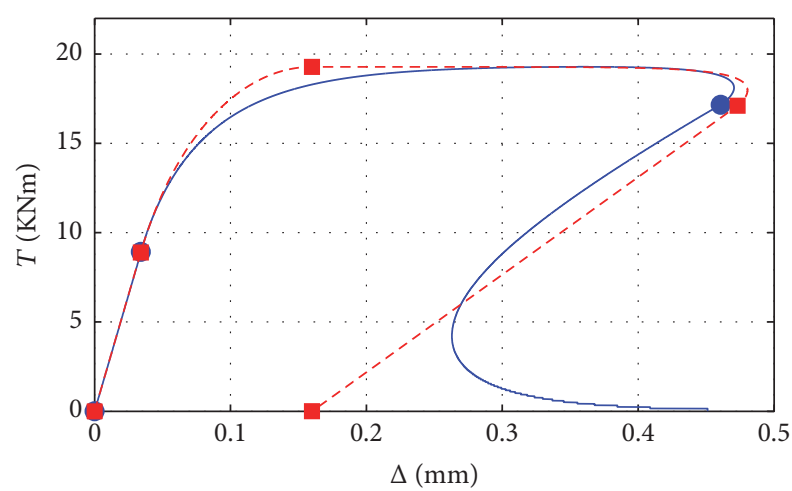

Exponential model

Bilinear model

(c) $L=60 \mathrm{~mm}$

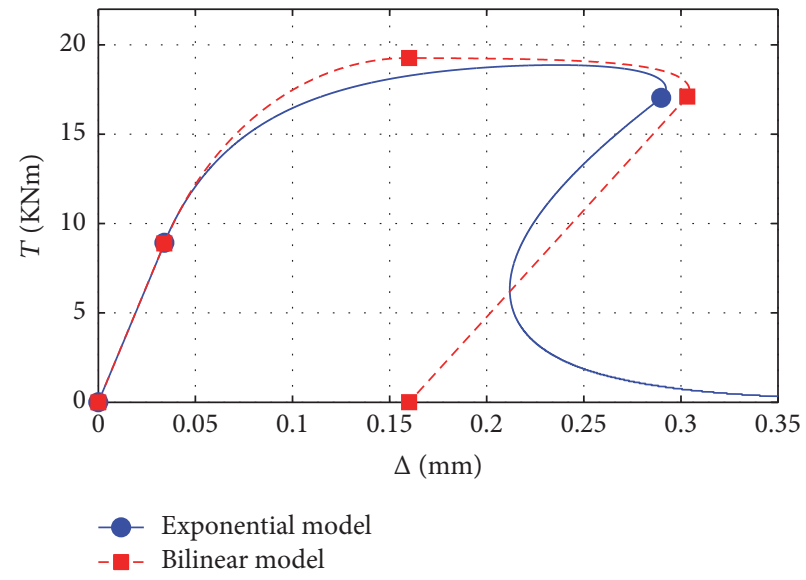

(b) $L=40 \mathrm{~mm}$

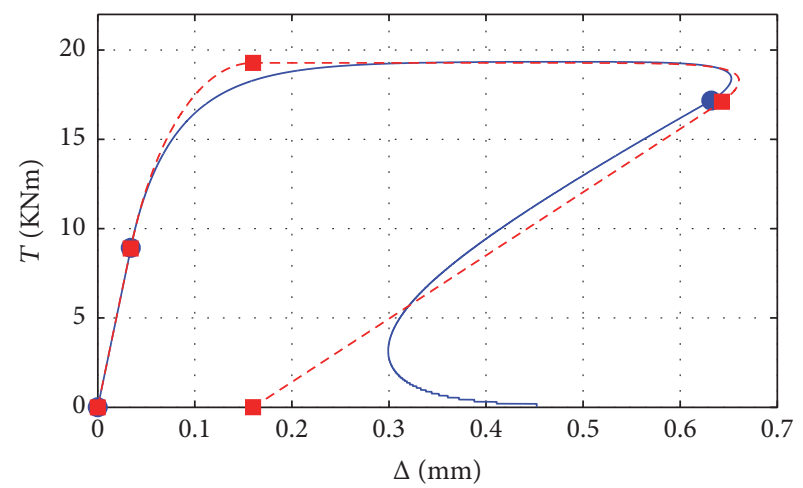

Exponential model

Bilinear model

(d) $L=80 \mathrm{~mm}$

FIGURE 9: Comparison of the load-displacement curves predicted from using the two bond-slip models.

bond length on the curves could be observed. In the range of the effective bond length, as the bond length increases, not only the interface failure processes change but also the ultimate load and interfacial slip. Specifically, the increase of the bond length can increase damage ductility. However, when the bond length reaches a certain length (effective bond length), the ultimate load will hardly change. Figure 8 (b) shows the influence for different bond lengths of exponential model on the load-displacement curves. From the figure we know that as the bond length increases the ultimate load increases. But the failure processes are all the same. Namely, the increase of the bond length can also increase damage ductility.

Figure 9 shows the comparison of the load-displacement curves between the two models for different bond lengths. The load-displacement curves are different when a softening area exists. In addition, since there is no debonding situation in the exponential model, the displacement can increase unlimitedly, with this being different from bilinear model in which the slip would approach $\delta_{f}$. From the figures, the load increases faster in the bilinear model as the bond lengths increases. However, when the bond length is long, the ultimate loads between the two models seem no more different.

Figure 10 shows the load-displacement curves for different ratios of torsion stiffness $\left(\beta=\left(G_{2} J_{2}\right) /\left(G_{1} J_{1}\right)\right)$. From the figures we can see that as the ratio increases, the ultimate load increases but the slip decreases; namely, the ductility reduces. Moreover, the larger the ratio is, the smaller the change magnitude will be.

Figure 11 shows the relationship of effective bond length and ratio of torsion stiffness. From the figure we can see that a stiffer coupler leads to a longer effective bond length. But as the ratio is getting larger, the effective bond length does not obviously increase. As the ratio increases, the effective bond lengths of two models have the similar trend, but the effective bond length of exponential model is longer than that of bilinear model.

Through the numerical computation, the ultimate load of exponential and bilinear models for different bond lengths could be obtained. Figure 12 shows the ultimate load for different bond lengths. From the figure we can see that, for bilinear model, when the bond length is short, the ultimate load increases significantly with the bond length. When 


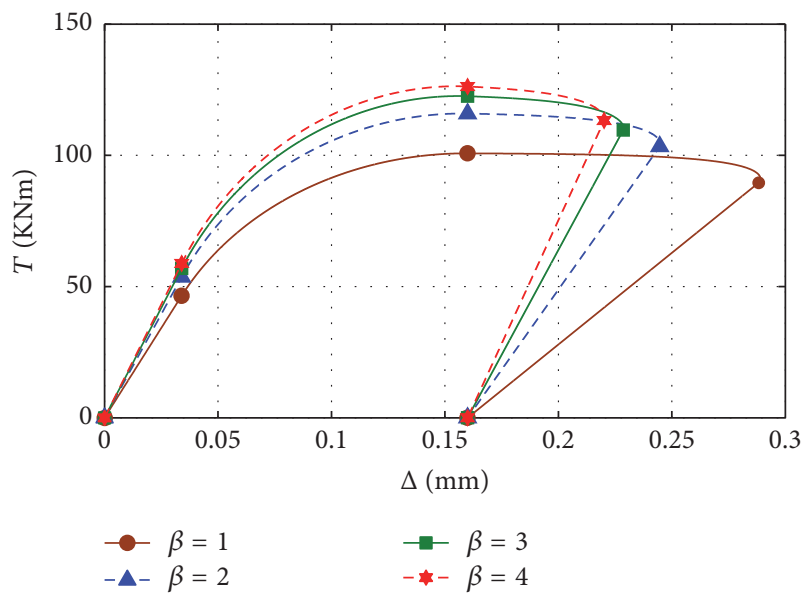

(a) Bilinear model

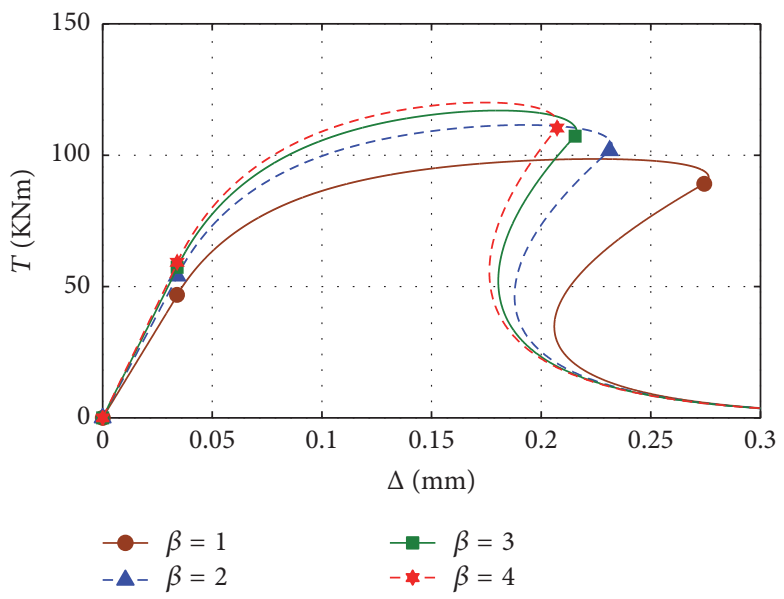

(b) Exponential model

FIGURE 10: Effect of torsion stiffness on the load-displacement curve.

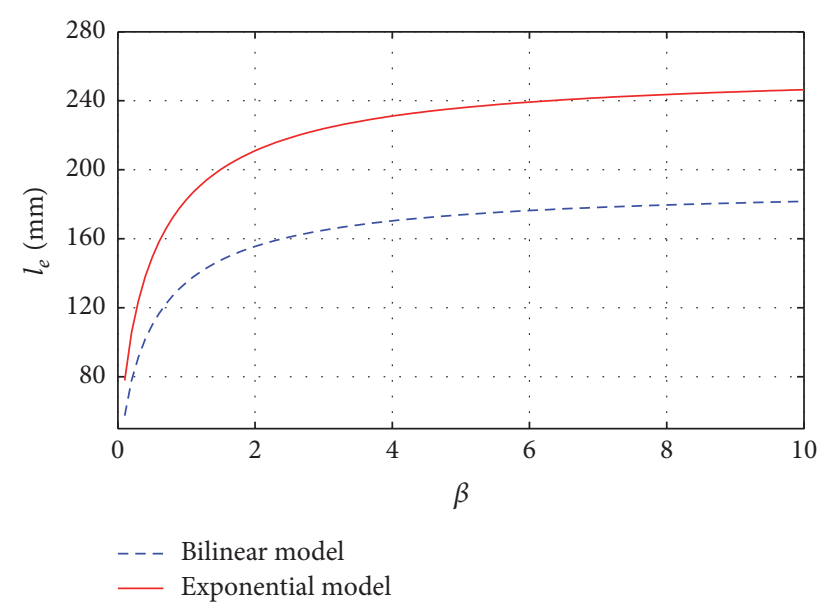

FIGURE 11: Effect of the torsion stiffness ratio on the effective bond length.

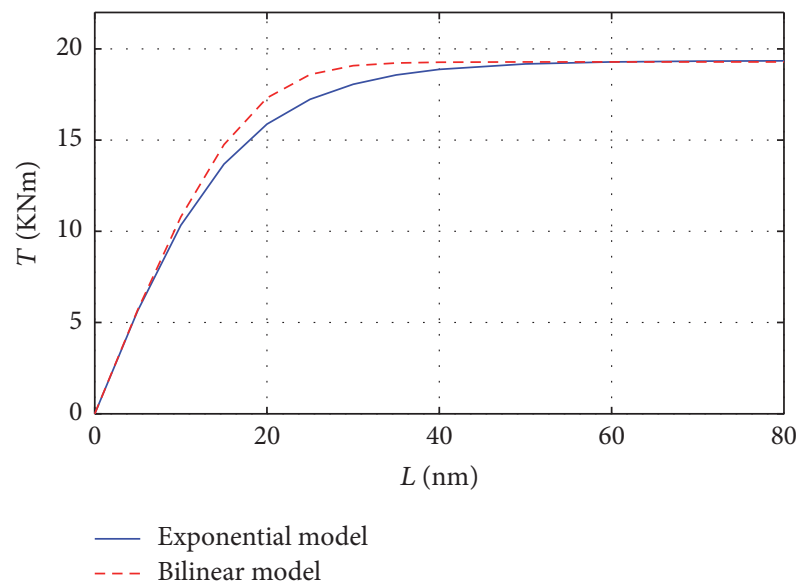

FIGURE 12: Effect of the bond length on the ultimate load.

the bond length is long, the ultimate load stays essentially unchanged. For the exponential model, when the bond length is short, the trend is similar to the bilinear model, but the ultimate load is relatively smaller. Both models have the same ultimate load when the bond length is relatively long.

\section{Conclusions}

On the basis of fully understanding the mechanical behavior of the joint interface, this paper gives a further understanding of the key factors of interfacial debonding. By modifying different shear moduli, the present results may be further extended to composite pipe joints, composite-metal pipe joints, or metallic pipe joints. Based on the derivations in the current study, some important conclusions are summarized as follows:

(1) Through the nonlinear fracture mechanics, the analytical expressions of the interfacial shear stress and the load-displacement relationship at loaded end of pipe joints under torsion loads could be gotten. Thus the shear stress propagation and the debonding progress of the whole interface for different bond lengths could be predicted.

(2) The influences of different bond length on the loaddisplacement curve and the ultimate load are studied through the analytical solutions. The stress transfer mechanism, the interface crack propagation, and the ductility behavior of the joints could be explained.

\section{Competing Interests}

The authors declare that they have no competing interests.

\section{Acknowledgments}

The authors gratefully acknowledge the financial support provided by the Science and Technology Scheme of Guangzhou City (201510010013), Science and Technology Scheme of Guangdong Province (2012A030200003), and the Natural 
Science Foundation of China (National Key Project no. 11032005).

\section{References}

[1] E. Dragoni and L. Goglio, "Adhesive stresses in axially-loaded tubular bonded joints-part I: critical review and finite element assessment of published models," International Journal of Adhesion and Adhesives, vol. 47, pp. 35-45, 2013.

[2] Z. Y. Ouyang and G. Q. Li, "Interfacial debonding of pipe joints under torsion loads: a model for arbitrary nonlinear cohesive laws," International Journal of Fracture, vol. 155, no. 1, pp. 19-31, 2009.

[3] Z. Ouyang and G. Li, "Cohesive zone model based analytical solutions for adhesively bonded pipe joints under torsional loading," International Journal of Solids and Structures, vol. 46, no. 5, pp. 1205-1217, 2009.

[4] C. Yang and Z. Guan, "Stress analysis of composite pipe joints under combined torsional and tensile loading," Journal of Pressure Vessel Technology, vol. 131, no. 5, Article ID 051210, 2009.

[5] Y. Zhao and S. S. Pang, "Stress-strain and failure analyses of composite pipe under torsion," Journal of Pressure Vessel Technology, Transactions of the ASME, vol. 117, no. 3, pp. 273-278, 1995.

[6] G. P. Zou and F. Taheri, "Stress analysis of adhesively bonded sandwich pipe joints subjected to torsional loading," International Journal of Solids and Structures, vol. 43, no. 20, pp. 59535968, 2006.

[7] N. Pugno and G. Surace, “Tubular bonded joint under torsion: theoretical analysis and optimization for uniform torsional strength," The Journal of Strain Analysis for Engineering Design, vol. 36, no. 1, pp. 17-24, 2001.

[8] J. Cheng and G. Li, "Stress analyses of a smart composite pipe joint integrated with piezoelectric composite layers under torsion loading," International Journal of Solids and Structures, vol. 45, no. 5, pp. 1153-1178, 2008.

[9] J. H. Oh, "Strength prediction of tubular composite adhesive joints under torsion," Composites Science and Technology, vol. 67, no. 7-8, pp. 1340-1347, 2007.

[10] R. Hosseinzadeh and F. Taheri, "Non-linear investigation of overlap length effect on torsional capacity of tubular adhesively bonded joints," Composite Structures, vol. 91, no. 2, pp. 186-195, 2009.

[11] R. Hosseinzadeh, N. Cheraghi, and F. Taheri, "An engineering approach for design and analysis of metallic pipe joints under torsion by the finite element method," The Journal of Strain Analysis for Engineering Design, vol. 41, no. 6, pp. 443-452, 2006.

[12] R. Hosseinzadeh, K. Shahin, and F. Taheri, "A simple approach for characterizing the performance of metallic tubular adhesively-bonded joints under torsion loading," Journal of Adhesion Science and Technology, vol. 21, no. 16, pp. 1613-1631, 2007.

[13] R. A. Esmaeel and F. Taheri, "Influence of adherend's delamination on the response of single lap and socket tubular adhesively bonded joints subjected to torsion," Composite Structures, vol. 93, no. 7, pp. 1765-1774, 2011.

[14] W. Xu and G. Q. Li, "Finite difference three-dimensional solution of stresses in adhesively bonded composite tubular joint subjected to torsion," International Journal of Adhesion \& Adhesives, vol. 30, no. 4, pp. 191-199, 2010.
[15] A. Hillerborg, M. Modéer, and P.-E. Petersson, "Analysis of crack formation and crack growth in concrete by means of fracture mechanics and finite elements," Cement and Concrete Research, vol. 6, no. 6, pp. 773-781, 1976.

[16] A. Needleman, "Continuum model for void nucleation by inclusion debonding," Journal of Applied Mechanics, Transactions $A S M E$, vol. 54, no. 3, pp. 525-531, 1987.

[17] V. Tvergaard and J. W. Hutchinson, “The relation between crack growth resistance and fracture process parameters in elasticplastic solids," Journal of the Mechanics and Physics of Solids, vol. 40, no. 6, pp. 1377-1397, 1992.

[18] J. Dai, T. Ueda, and Y. Sato, "Development of the nonlinear bond stress-slip model of fiber reinforced plastics sheet-concrete interfaces with a simple method," Journal of Composites for Construction, vol. 9, no. 1, pp. 52-62, 2005.

[19] B. Täljsten, "Strengthening of concrete prisms using the platebonding technique," International Journal of Fracture, vol. 82, no. 3, pp. 253-266, 1996.

[20] R. Xu and C. Liu, "CZM-based debonding simulation of cracked beams strengthened by FRP sheets," Journal of Engineering Mechanics, vol. 138, no. 2, pp. 210-220, 2011.

[21] S.-K. Woo and Y. Lee, "Experimental study on interfacial behavior of CFRP-bonded concrete," KSCE Journal of Civil Engineering, vol. 14, no. 3, pp. 385-393, 2010.

[22] C. Mazzotti, M. Savoia, and B. Ferracuti, "An experimental study on delamination of FRP plates bonded to concrete," Construction and Building Materials, vol. 22, no. 7, pp. 1409-1421, 2008.

[23] B. Ferracuti, M. Savoia, and C. Mazzotti, "Interface law for FRPconcrete delamination," Composite Structures, vol. 80, no. 4, pp. 523-531, 2007.

[24] T. Yu, D. Fernando, J. G. Teng, and X. L. Zhao, "Experimental study on CFRP-to-steel bonded interfaces," Composites Part B: Engineering, vol. 43, no. 5, pp. 2279-2289, 2012.

[25] J. F. Chen, H. Yuan, and J. G. Teng, "Debonding failure along a softening FRP-to-concrete interface between two adjacent cracks in concrete members," Engineering Structures, vol. 29, no. 2, pp. 259-270, 2007.

[26] V. Narayanamurthy, J. F. Chen, J. Cairns, and D. J. Oehlers, "Plate end debonding in the constant bending moment zone of plated beams," Composites Part B: Engineering, vol. 43, no. 8, pp. 33613373, 2012.

[27] H. Yuan, J. F. Chen, J. G. Teng, and X. Z. Lu, "Interfacial stress analysis of a thin plate bonded to a rigid substrate and subjected to inclined loading," International Journal of Solids and Structures, vol. 44, no. 16, pp. 5247-5271, 2007.

[28] J. G. Teng, H. Yuan, and J. F. Chen, "FRP-to-concrete interfaces between two adjacent cracks: theoretical model for debonding failure," International Journal of Solids and Structures, vol. 43, no. 18-19, pp. 5750-5778, 2006.

[29] H. Yuan, X. Lu, D. Hui, and L. Feo, "Studies on FRP-concrete interface with hardening and softening bond-slip law," Composite Structures, vol. 94, no. 12, pp. 3781-3792, 2012.

[30] D. Fernando, T. Yu, and J. G. Teng, "Behavior of CFRP laminates bonded to a steel substrate using a ductile adhesive," Journal of Composites for Construction, vol. 18, no. 2, Article ID 04013040, 2014.

[31] Z. Wu, H. Yuan, and H. Niu, "Stress transfer and fracture propagation in different kinds of adhesive joints," Journal of Engineering Mechanics, vol. 128, no. 5, pp. 562-573, 2002. 
[32] H. Yuan, J. G. Teng, R. Seracino, Z. S. Wu, and J. Yao, "Fullrange behavior of FRP-to-concrete bonded joints," Engineering Structures, vol. 26, no. 5, pp. 553-565, 2004.

[33] A. Caggiano, E. Martinelli, and C. Faella, "A fully-analytical approach for modelling the response of FRP plates bonded to a brittle substrate," International Journal of Solids and Structures, vol. 49, no. 17, pp. 2291-2300, 2012.

[34] F. Chen and P. Qiao, "Debonding analysis of FRP-concrete interface between two balanced adjacent flexural cracks in plated beams," International Journal of Solids and Structures, vol. 46, no. 13, pp. 2618-2628, 2009.

[35] L. De Lorenzis and G. Zavarise, "Cohesive zone modeling of interfacial stresses in plated beams," International Journal of Solids and Structures, vol. 46, no. 24, pp. 4181-4191, 2009.

[36] P. Cornetti and A. Carpinteri, "Modelling the FRP-concrete delamination by means of an exponential softening law," Engineering Structures, vol. 33, no. 6, pp. 1988-2001, 2011.

[37] J. F. Chen and J. G. Teng, "Anchorage strength models for FRP and steel plates bonded to concrete," Journal of Structural Engineering, vol. 127, no. 7, pp. 784-791, 2001. 


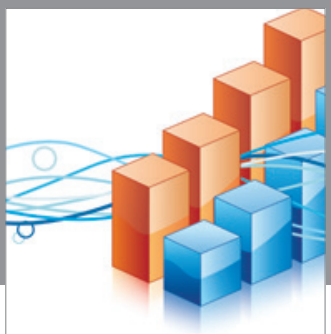

Advances in

Operations Research

vatem alat4

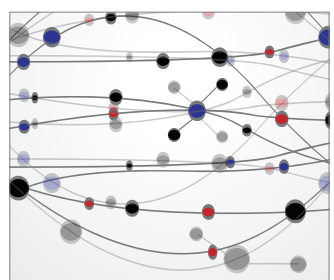

\section{The Scientific} World Journal
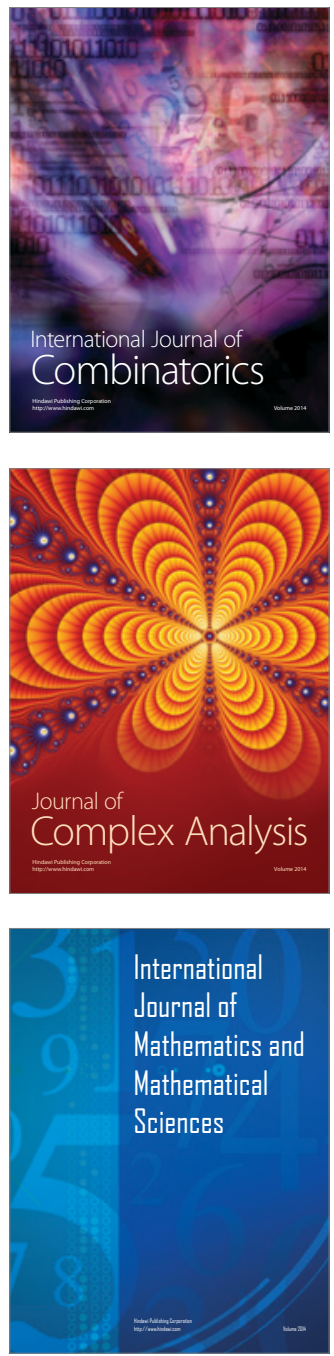
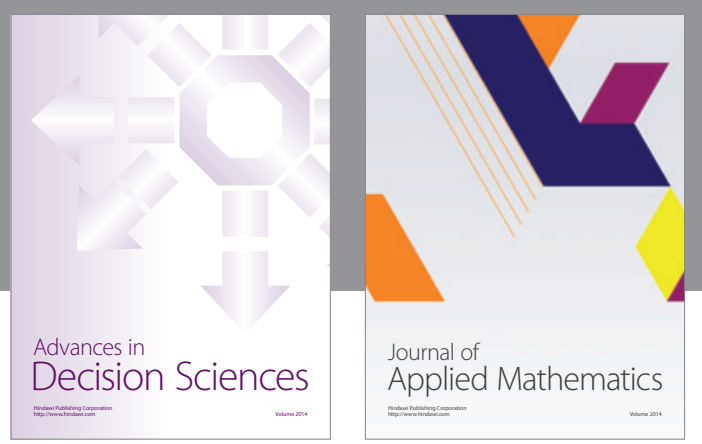

Algebra

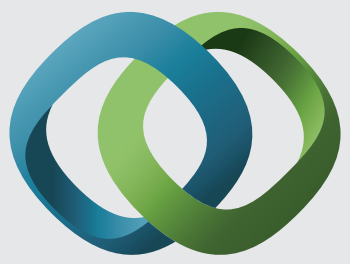

\section{Hindawi}

Submit your manuscripts at

http://www.hindawi.com
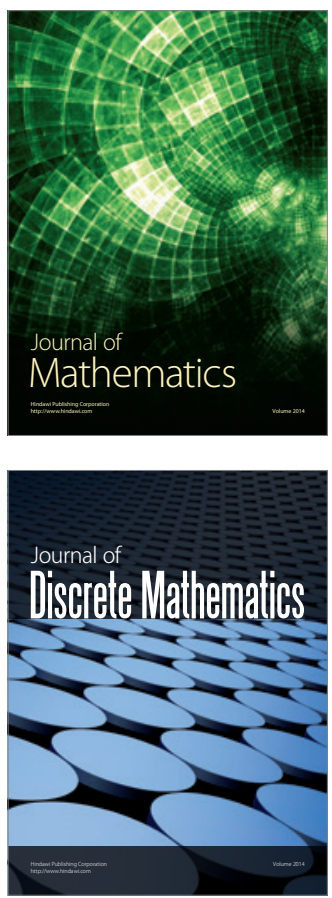

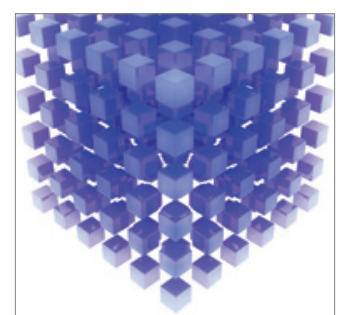

Mathematical Problems in Engineering
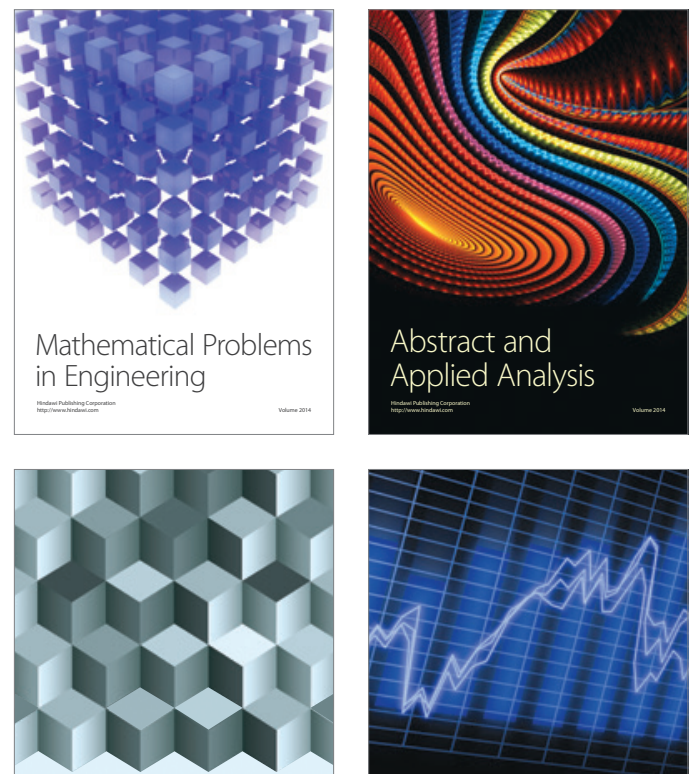

Journal of

Function Spaces

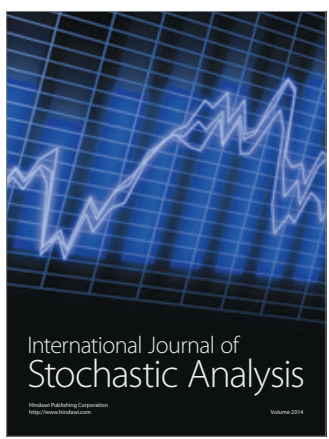

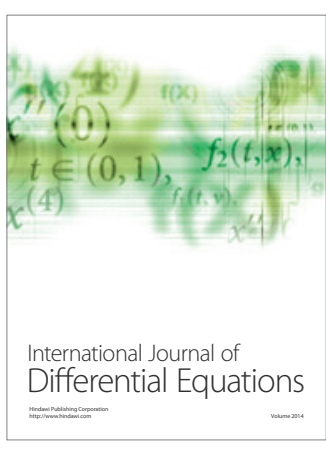
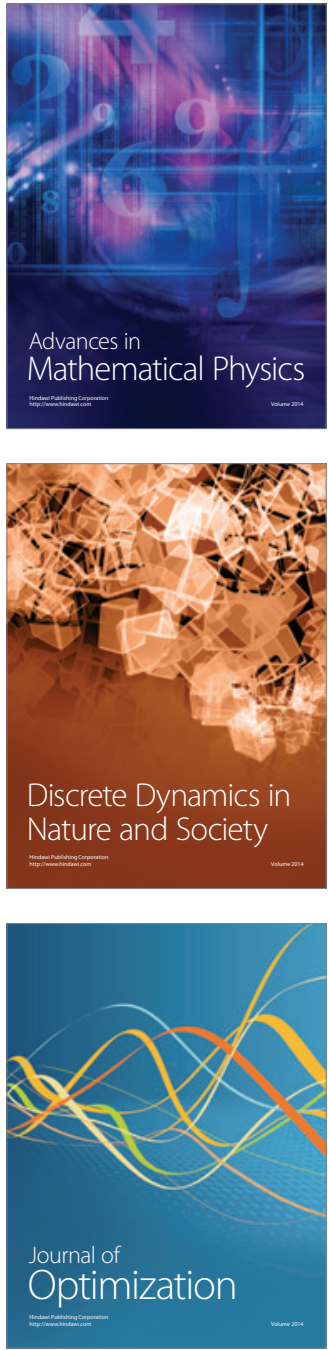